\title{
Antiproteinase chemotherapy of acute experimental pancreatitis using the low molecular weight oligopeptide aldehyde leupeptin
}

\author{
P A JONES, ${ }^{*}$ J HERMON-TAYLOR, and D A W GRANT \\ From the Department of Surgery, St George's Hospital Medical School, London
}

\begin{abstract}
SUMMARY Continuous intravenous infusion of the low molecular weight trypsin inhibitor leupeptin prolonged the survival of rats with acute haemorrhagic pancreatitis $(\mathrm{p}<0 \cdot 001)$ compared with controls receiving saline alone. Rats receiving high dose intravenous Trasylol (aprotinin) survived no longer than saline-only controls. Combination therapy of leupeptin with Trasylol conferred no additional benefit over animals treated with leupeptin alone. The nature of the infusion was selected blind after the induction of pancreatitis and survival was quantified by recording of body temperature. These preliminary results suggest that sterically favourable molecules which can complete the inhibition of $\alpha_{2}$-macroglobulin bound proteinases should contribute to the effective specific chemotherapy of the disease.
\end{abstract}

It is generally accepted that a crucial event in the pathogenesis of acute necrotising pancreatitis is the overwhelming and inappropriate activation of digestive zymogens within the gland leading to the autodigestion of pancreatic tissue and the massive dissemination of active enzymes. ${ }^{1-5}$ In health such events are prevented by the biosynthesis of inactive precursor forms of the most dangerous enzymes and their storage in membrane-bound granules within the acinar cells. Release of these zymogens into the pancreatic ducts and their subsequent activation only within the gut lumen is a further safeguard. The acinar cell also produces trypsin inhibitors which complex with active free trypsin preventing the protentially disastrous activation of the other proenzymes. ${ }^{16}$ If free trypsin, chymotrypsin, and elastase are released into blood they immediately complex with the serum proteinase inhibitors, $\alpha_{1^{-}}$ antiproteinase and $\alpha_{2}$-macroglobulin. ${ }^{7-10}$ The $\alpha_{1}$ antiproteinase-enzyme complex is catalytically inert but the $\alpha_{2}$-macroglobulin-enzyme complex retains a proportion of esterolytic and proteolytic activity against substrates of varying molecular size. ${ }^{11-13}$ Normally these complexes are rapidly eliminated from the circulation by the reticuloendothelial

\footnotetext{
* Present address and address for correspondence: Mr P A Jones, Westminster Hospital, London, SW1

Received for publication 26 February 1982
}

system and circulating tryptic activity is insignificant. ${ }^{14} 15$ In severe acute pancreatitis the capacity to remove the catalytic complexes is exceeded; ${ }^{16}$ necrosis of pancreatic parenchyma, haemorrhage, and metastatic proteolytic damage occur and are associated with a high mortality. ${ }^{17}$

We have recently obtained good evidence to suggest that the reason that the protein antiproteinase Trasylol (aprotinin, $K_{i}$ for free trypsin $3 \times 10^{-11} \mathrm{M}$ ) is ineffective in acute necrotising pancreatitis is because the molecule is both too large (6400 daltons) and too inflexible to inhibit the catalytic activity of $\alpha_{2}$-macroglobulin bound proteinases against biologically important substrates. ${ }^{18}$ Inhibition of these catalytic complexes was, however, completed by the low molecular weight oligopeptide aldehydes leupeptin (474 daltons) and antipain (674 daltons); this suggests that these inhibitors might contribute effectively to the specific chemotherapy of acute necrotising pancreatitis. ${ }^{18}$ Leupeptin and antipain belong to a series of oligopeptide proteinase inhibitors produced by specific strains of streptomyces. ${ }^{19}$ They have been isolated and characterised by Umezawa and co-workers ${ }^{20} 21$ and shown to be potent competitive inhibitors of many enzymes including trypsin, thrombin, plasmin, some lysozomal hydrolases, and papain. This paper reports the effect of a partly purified preparation of one of these oligopeptide inhibitors, leupeptin, on the course of 
acute haemorrhagic pancreatitis in rats and compares the results with those obtained using the protein antiproteinase Trasylol.

\section{Methods}

Leupeptin was kindly provided by Professor $\mathrm{H}$ Umezawa, Institute fo Microbial Chemistry, Tokyo, Japan; sodium taurocholate was obtained from BDH Chemicals, Poole, Dorset, UK, and used without further purification. 2x-crystallised bovine trypsin was from Sigma Chemicals, Poole, Dorset, UK. Trasylol was from Bayer (UK) Hayward's Heath, Sussex, and Biogel P2 was from Bio-Rad Laboratories, Watford, Herts, UK.

\section{CHROMATOGRAPHY AND TOXICITY TESTING OF} LEUPEPTIN

Two hundred milligram aliquots of the partly purified preparation of leupeptin were solubilised in $1 \mathrm{ml} 50 \mathrm{mM}$ acetic acid and fractionated on a $185 \mathrm{ml}$ bed of Biogel P2. The column eluate was monitored at $220 \mathrm{~nm}$ and the material was divided into four fractions, lyophilised, and characterised by thin layer chromatography. ${ }^{20}$ Each fraction was tested for acute toxicity in vivo.

Two hundred and fifty gram male Wistar Firth rats were anaesthetised with intraperitoneal pentobarbitone sodium $(6 \mathrm{mg} / 100 \mathrm{~g}$ body weight $)$ and the left femoral artery and vein were cannulated. The arterial line was connected to a pressure transducer and the blood pressure was monitored on a recorder; respiration was also observed. Aliquots of the four leupeptin fractions varying from $2 \mathrm{mg} / \mathrm{kg}$ to $20 \mathrm{mg} / \mathrm{kg}$ body weight were administered as single doses intravenously over a one minute period.

\section{STANDARDISED INDUCTION OF ACUTE}

PANCREATITIS IN RATS

A modification of Lankisch's method ${ }^{22}$ was used in the induction of acute pancreatitis. Male Wistar Firth rats weighing between $230-270 \mathrm{~g}$ were anaesthetised with intraperitoneal pentobarbitone sodium $(6 \mathrm{mg} / 100 \mathrm{~g}$ body weight $)$ and the duodenum delivered through a midline abdominal incision. The proximal end of the common bile duct was occluded by a $8 \times 1.5 \mathrm{~mm}$ Codman straight neurosurgical aneurysm clip (Hamblin Instruments, London) and the distal end cannulated by transduodenal puncture with a 22 gauge Argyll medicut Teflon cannula, held in place by an encircling suture. A standardised intraduct infusion of $2 \mathrm{ml}$ per $\mathrm{kg}$ body weight of $3.5 \%(\mathrm{w} / \mathrm{v})$ sodium taurocholate containing 6000 BAEE units of trypsin per $\mathrm{ml}$ of isotonic saline and 2 $\mathrm{mM} \mathrm{CaCl} 2$ was delivered from a syringe drive pump at $0.05 \mathrm{ml} / \mathrm{min}$. Techniques were developed to permit continuous intravenous infusion ${ }^{23}$ and body temperature monitoring in the unrestrained animals. ${ }^{24}$ From this record the time of death could be precisely identified by the exponential fall in body temperature.

INTRAVENOUS INFUSIONS AND QUANTIFICATION OF SURVIVAL

In group A 15 rats received an intravenous dose of 9000 units of Trasylol on wound closure followed by 3500 units/h at an infusion rate of $1 \mathrm{ml} / \mathrm{h} ; 15$ control animals received an equal volume of saline alone. In group B 15 rats received an intravenous dose of $0 \cdot 2$ $\mathrm{mg}$ of the fractionated leupeptin before an hourly infusion of $0.2 \mathrm{mg}$ of the same material; an additional 15 rats received saline alone. In group C 15 rats were given 9000 units of Trasylol together with $0.2 \mathrm{mg}$ leupeptin on wound closure followed by an hourly infusion of 3500 units of Trasylol and $0 \cdot 2$ mg leupeptin; 15 animals received leupeptin alone on an identical dosage regime to those in group B; and 15 control animals again received equivalent volumes of saline alone. At the time of induction of pancreatitis the nature of the intravenous infusion (test or control) was not known and was selected subsequently for each animal by drawing a coloured disc. The presence or absence of therapeutic effect was based upon duration of survival measured on the trace to the nearest hour. Survival times were compared using a two sample Student's $t$ test.

\section{Results}

FRACTIONATION AND TOXICITY TESTING OF LEUPEPTIN

The elution profile of partly purified leupeptin on Biogel P2 chromatography is shown in Fig. 1. Of the four pooled fractions I, II, and III were toxic to rats; I had an $L^{2} D_{50}$ of $\sim 10 \mathrm{mg} / \mathrm{kg}$ body weight, and fractions II and III had an $\mathrm{LD}_{50}$ of $\sim 20 \mathrm{mg} / \mathrm{kg}$ body weight when given as an intravenous dose over a one minute period. The animals died within two minutes of administration from simultaneous apnoea and severe hypotension. Fractions II and III contained the anti-trypsin activity $\left(\mathrm{K}_{\mathrm{i}} \sim 1.25 \mu \mathrm{M}\right)$ and were combined and used for subsequent in vivo studies. Thin layer chromatographic analysis consistently showed two spots at the predicted $R_{f}$ values for acetyl- and propionyl-leupeptin. ${ }^{20}$

SURVIVAL AFTER INDUCTION OF PANCREATITIS Figure $2 \mathrm{a}$ shows that Trasylol had no beneficial effect on survival in acute pancreatitis compared with the continuous intravenous infusion of saline alone (group A). Mean survival time in hours \pm ISD was $25 \cdot 4 \pm 10 \cdot 5$ for the saline group and $25 \cdot 7 \pm 9 \cdot 9$ for 


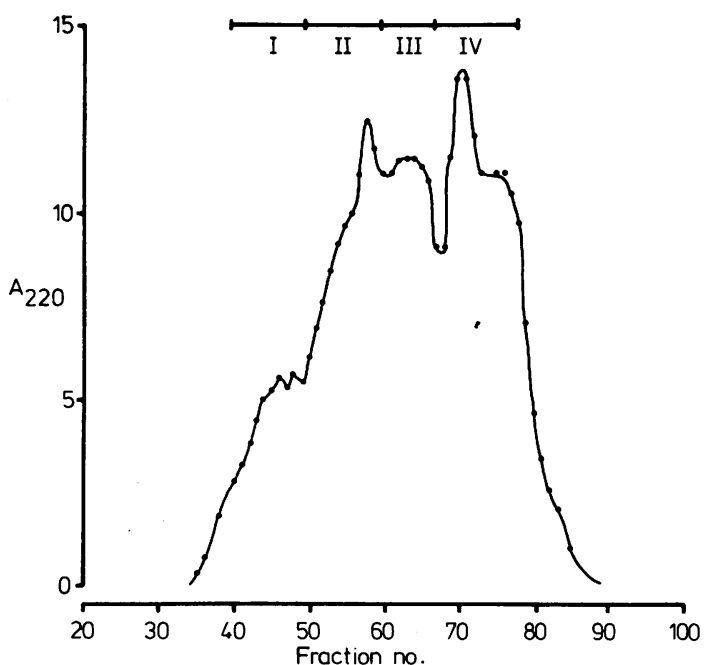

Fig. 1 Elution profile of partly purified leupeptin after chromatography on a column of Biogel P2 $(2.54 \times 37 \mathrm{~cm}) 2$ $\mathrm{ml}$ fractions pooled I-VI as indicated. For details see text.

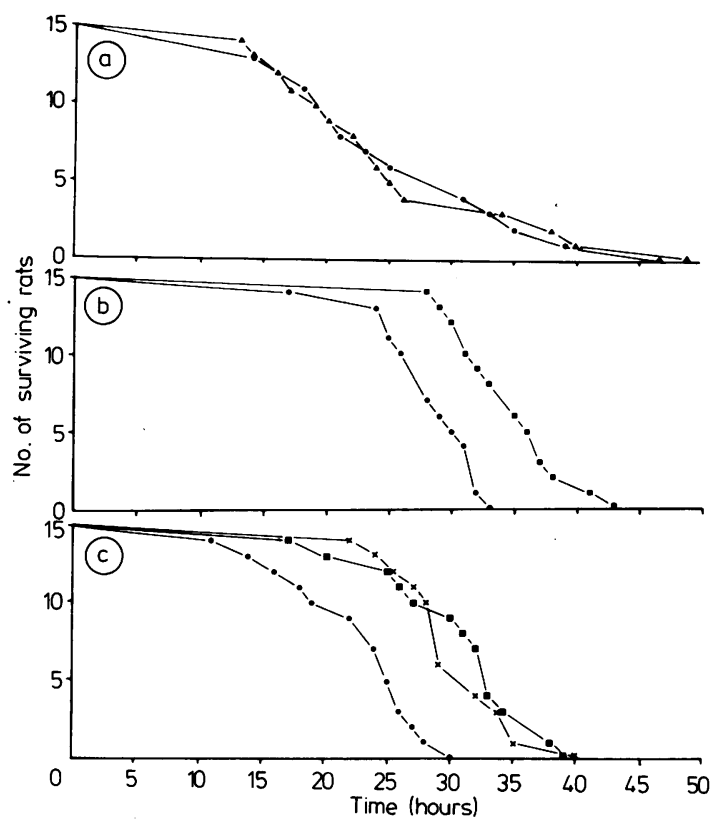

Fig. 2 Survival times of rats with acute pancreatitis receiving continuous intravenous infusions of either (a)

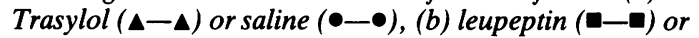
saline, (c) leupeptin with Trasylol $(x-x)$, leupeptin alone, or saline. For dosages see Methods section. the Trasylol group. Figure $2 \mathrm{~b}$ shows that rats receiving continuous intravenous leupeptin as described survived longer than those receiving saline alone (group B). Mean survival time in hours \pm ISD was $28 \cdot 0 \pm 4 \cdot 2$ for the saline controls and $34 \cdot 4 \pm 4 \cdot 4$ for the leupeptin treated animals; this difference was statistically significant $(\mathrm{p}<0 \cdot 001)$. No additional benefit was conferred by including Trasylol in the leupeptin infusion (group C) (Fig. 2c). Mean survival time in hours \pm ISD were $22 \cdot 3 \pm 5 \cdot 5$ for the control rats, $30.0 \pm 4.8(\mathrm{p}<0.001)$ for the combined leupeptin/Trasylol treated animals, and 30.4 $\pm 6 \cdot 4$ $(p<0.001)$ for the rats receiving leupeptin alone. There was no significant difference in group $\mathrm{C}$ between the rats receiving the combination therapy of leupeptin and Trasylol and those just receiving leupeptin $(\mathrm{p}>0 \cdot 5)$.

\section{Discussion}

The method described here for the standardised induction of acute haemorrhagic pancreatitis is a modification of that described by Lankisch et al. ${ }^{22}$ Accurate, automated monitoring of survival times revealed, in preliminary studies, the poor reproducibility associated with manual intraductal injection. This was not apparent when only the 24-hour survivors were scored. ${ }^{22}$ Therefore mechanised, continuous, slow intraductal infusion was developed which, within each group, provided good reproducibility. Because of the inherently variable susceptibilities of any experimental animal, particularly over the duration of this type of study, care was taken to match equal numbers of control and treated animals on the same day.

Many specific treatments have been tried in acute pancreatitis with two principal objectives: either the inhibition or removal of disseminated active enzymes or the prevention of further zymogen biosynthesis and release by pancreatic acinar cells. ${ }^{17}$ 25-31 Therapies described in the former category include peritoneal lavage ${ }^{17}$ and the administration of antiproteinases, ${ }^{25} 26$ whereas anticholinergics, ${ }^{27}$ glucagon, ${ }^{26}$ calcitonin, ${ }^{28}$ and somatostatin $^{29}$ are in the latter group. In all cases results have at best been equivocal and no therapy has been demonstrated to consistently reduce morbidity or mortality of the disease. Metastatic proteolytic damage by disseminated $\alpha_{2}-$ macroglobulin-pancreatic-proteinase complexes in acute necrotising pancreatitis will be maximal in the early hours of the disease when mortality is highest and the need for effective specific treatment is most urgent. Three recent randomised clinical trials have shown that Trasylol fails to confer benefit over standard conservative management of patients with 
acute pancreatitis. ${ }^{25} 2632$ This is most likely because of the inability of Trasylol to inhibit the activity of trypsin complexed with $\alpha_{2}$-macroglobulin due to its failure to gain access to the shielded catalytic site. ${ }^{18}$ Susceptible peptide hormones such as glucagon and somatostatin, infused during this period of severe acute pancreatitis will be rapidly degraded by catalytic $\alpha_{2}$-macroglobulin enzyme complexes against which Trasylol will afford little protection. The use of low-molecular weight anti-proteinase would appear to be advantageous, as they should be independent of these steric constraints.

In this study Trasylol was without effect in prolonging the survival of rats with experimental pancreatitis despite its early administration and continuous intravenous infusion at $5 \times$ the recommended clinical dose for man. Intravenous leupeptin resulted in an extension of survival; although this effect was statistically significant, none of the leupeptin treated rats eventually survived. Further studies using highly purified leupeptin are clearly indicated, as residual toxic components may have contributed to mortality in the leupeptin treated animals and certainly limited the dose of the inhibitor that could be used, but these are preliminary findings and form the basis of a continuing study into the use of peptide aldehyde protease inhibitors in the treatment of acute pancreatitis. We would suggest that a combination of different low molecular weight inhibitors, either of bacterial origin or custom synthesised, with a wide spectrum of specificities for the digestive proteases could become an effective treatment for this disease.

We would like to express our gratitude to Professor Hamao Umezawa and Dr Takaaki Aoyagi, Institute of Microbial Chemistry, Tokyo, for the gift of leupeptin and to Dr Alan Barrett, Strangeways Laboratory, Cambridge, for his help. Financial support was graciously given by the Wellcome Trust and the St George's Hospital Medical Research Committee.

\section{References}

1 Haverback BJ, Dyce B, Bundy H, Edmonson HA. Trypsin, trypsinogen and trypsin inhibitor in human pancreatic juice. Mechanism for pancreatitis associated with hyperparathyroidism. Am J Med 1960; 29: 424-33.

2 Geokas MC, Rinderknecht $H$. Free proteolytic enzymes in pancreatic juice of patients with acute pancreatitis. Am J Dig Dis 1974; 19: 591-8.

3 Schmidt H, Creutzfeldt W. Etiology and pathogenesis of pancreatitis. In: Bockus HL, ed. Gastroenterology London: Saunders, 1976: 1005-19.

4 Hermon-Taylor J. An aetiological and therapeutic review of acute pancreatitis. BrJ Hosp Med 1976; 18: 546-52.

5 Durr GH. Acute pancreatitis. In: Howat HT, Sarles H, eds. The exocrine pancreas London: Saunders, 1979: 352-401.

6 Grossman MI. Some properties of the trypsin inhibitor of pancreatic juice. Proc Soc Exp Biol Med 1958; 99: 304-6.

7 Barrett AJ, Starkey PM. The interaction of $\alpha_{2}$-macroglobulin with proteinases. Biochem J 1973; 133: 70924.

8 Harpel PC. Studies on human plasma $\alpha_{2}$ macroglobulin-enzyme interactions. J Exp Med 1973 138: 508-21.

9 Ohlsson K, Ganrot PO, Laurell CB. In vivo interaction between trypsin and some plasma proteins in relation to tolerance to intravenous infusion of trypsin in dog. Acta Chir Scand 1971; 137: 113-21.

10 Balldin G, Ohlsson K. Demonstration of pancreatic protease-antiproteinase complexes in the peritoneal fluid of patients with acute pancreatitis. Surgery 1979; 85: 451-6.

11 Ganrot PO. $\alpha_{2}$-antitrypsin activity and different trypsin substrates. Clin Chim Acta 1966; 13: 518-21.

12 Harpel PC, Mosesson MW. Degradation of human fibrinogen by plasma $\alpha_{2}$-macroglobulin-enzyme complexes. J Clin Invest 1973; 52: 2175-84.

13 Rinderknecht $\mathrm{H}$, Geokas MC. On the physiological role of $\alpha_{2}$-macroglobulin. Biochim Biophys Acia 1973; 295: $233-44$.

14 Ohlsson K. Elimination of ${ }^{125}$ I-trypsin $\alpha$-macroglobulin complexes from blood by reticuloendothelial cells in dog. Acta Physiol Scand 1971; 8: 269-72.

15 Grant DAW, Fleming SC. The biliary excretion of trypsin in rats. Biosc Rep 1981; 1: 765-70.

16 Worthington KJ, Cushieri A. Estimation of plasma esterolytic activity and its in vitro inhibition by proteinase inhibitors during acute pancreatitis in the human. Br J Exp Pathol 1976; 57: 165-9.

17 Ransom JHC, Rifkind KM, Roses DF, Fink SD, Eng $\mathrm{K}$, Spencer FC. Prognostic signs and the role of operative management in acute pancreatitis. Surg Gyn Obstet 1974; 139: 69-81.

18 Hermon-Taylor J, Magee AI, Grant DAW, Jones PA, Marshall CE, Dunham J. Cleavage of peptide hormones by $\alpha_{2}$-macroglobulin-trypsin complex and its relation to the pathogenesis and chemotherapy of acute pancreatitis. Clin Chim Acta 1981; 109: 203-9.

19 Umezawa $\mathrm{H}$, Aoyagi $\mathrm{T}$. Activities of proteinase inhibitors of microbial origin. In: Barrett $\mathrm{AJ}$ ed. Proteinases in mammalian cells and tissues. North Holland, pp 637-662, 1977.

20 Kondo S, Kawamura K, Iwanaga J, Hamada M, Aoyagi $T$, Maeda $K$, Takeuchi $T$, Umezawa $H$. Isolation and characterisation of leupeptins produced by actinomycetes. Chem Pharm Bull 1969; 17: 18961901.

21 Aoyagi T, Miyata S, Nanbo M, Kojima F, Matsuzaki M, Ishizuka M, Takeuchi T, Umezawa H. Biological 
activities of leupeptins. $J$ Antibiotics 1969; 22: 558-68.

22 Lankisch PG, Winckler K, Bokermann M, Schmidt H, Creutzfeldt $W$. The influence of glucagon on acute experimental pancreatitis in the rat. Scand $J$ Gastroenterol 1974; 9: 725-9.

23 Jones PA, Hynd JW. Continuous long-term intravenous infusion in the unrestrained rat - a novel technique. Lab Anim 1981; 15: 29-33.

24 Jones $P$. Automated estimation of survival in unrestrained rats. Lab Anim 1982; 16: 119-22.

25 MRC Working Party on the Treatment of Acute Pancreatitis. Deaths from acute pancreatitis. Lancet 1977; 2: 632-5.

26 MRC Multicentre Trial. Morbidity of acute pancreatitis: the effect of aprotinin and glucagon. Gut 1980; 21: 334-9.

27 Trapnell JC. The natural history and prognosis of acute pancreatitis. Ann Roy Coll Surg 1966; 38: 265-87.
28 Goebell H, Ammann R, Herforth CL, Hom J, Hotz J, Knoblauch $\mathbf{M}$ et al. A double-blind trial of synthetic salmon calcitonin in the treatment of acute pancreatitis. Scand J Gastroenterol 1979; 14: 881-9.

29 Lankisch PG, Koop H, Winckler K, Folsch U, Creutzfeld W. Somatostatin therapy of acute pancreatitis. Gut 1977; 18: 713-6.

30 Tykka H, Mahlberg K, Pantzar P, Tallberg T. Phospholipase $\mathrm{A}_{2}$ inhibitors and their possible clinical use in the treatment of acute pancreatitis. Scand $J$ Gastroenterol 1980; 15: 519-28.

31 Usadel K-H, Leuschner U, Uberla KK. Treatment of acute pancreatitis with somatostatin: a multicentre double-blind trial. $N$ Engl J Med 1980; 303: 999-1000.

32 Imrie CW, Benjamin IS, Ferguson JC, McKay AJ, Mackenzie I, O'Neill J, Blumgart LH. A single centre double-blind trial of Trasylol therapy in primary acute pancreatitis. Br J Surg 1978; 65: 337-41. 